\title{
Considerações sobre uma estética contemporânea
}

\author{
Prof. Dra Maria Beatriz Furtado Rahde ${ }^{1}$ \\ PUC-RS \\ frahde@portoweb.com.br \\ Jaqueline Dalpizzolo \\ PUC-RS \\ kinie_nh@hotmail.com
}

\begin{abstract}
Resumo: Este texto busca refletir sobre a passagem da modernidade para a pós-modernidade, na qual a importância da busca de uma nova concepção estética é uma realidade no mundo contemporâneo. A percepção estética da realidade pós-moderna busca a liberdade nas criações visuais não obedecendo a cânones, como acontecia em muitas tendências modernistas, mas caminha noutras direções, numa hibridação entre o real e o imaginário, que traduz, reinterpreta e, por isso mesmo, transforma tradicionais conceitos estéticos em novas possibilidades imagísticas.
\end{abstract}

Palavras-Chave: Pós-Modernidade-Estética - Imaginário

Abstract: This text is aimed at reflecting on the transition of modernity to post-modernity, whereby the urge for the search of a new esthetic concept is the reality in contemporary. The post modern a esthetic conception and it perception aimed the liberty and visual creations and do not obey rules as we can see in most modernists tendences but walk into others directions with an hybridation between reality and imaginary that we can see new transformations and others traductions of a esthetics concepts in another imagistics possibilities.

Key-words: Postmodernity - Esthetic - Imaginary

1 Dra em Educação FACED/PUCRS. Profa. Titular da Pontifícia Universidade Católica do Rio Grande do Sul - PPGCom/ FAMECOS/PUCRS. Linha de Pesquisa: Cultura Midiática e Tecnologias do Imaginário (CMTI).

2 Bolsista Iniciação Científica Projeto BIC - FAPERGS. Graduanda da Pontifícia Universidade Católica do Rio Grande do Sul. FACED - Pedagogia Multimeios e Informática Educativa. 
Résumé: Ce texte vise à réfléchir sur le passage de la modernité à la postmodernité, dans laquelle l'importance de la recherche d'une nouvelle conception esthétique est une réalité de la contemporaneité. La perception esthetique de la post-modernité cherche la liberté dans les criations visuelles sens obéir roules comme dans chaques tendences modernistes, mais transite d'autres directions avec l'hybridation parmi la realité et l'imaginaire, qui traduit, reinterprete et par ce motif c'est une transformation des tradicionelles conceptes esthetiques avec nouvelles possibilites iconographiques.

\section{Mots-clés: Post-modernité - Esthetique - Imaginaire}

Resumen: Este texto busca una reflexión sobre la transitoriedad de la modernidad hasta la postmodernidad en la qual la importancia de la procura de una nueva concepción estetica es uma realidad en el mundo contemporaneo. La persepción estetica de la realidad posmoderna esta procurando la libertad en las creaciones visuales sin obediencia a canones, cómo ocurria en muchas tendências modernistas, pero camina en otras direcciones, con hibridación entre realidad y imaginario, que traduz, reinterpreta, y por esso mismo, tranforma tradicionales conceptos esteticos en nuevas possibilidades imagisticas.

Palabras-llave: Postmodernidad - Estetica - Imaginario.

\section{Contextualização}

O ser humano que foi mais racional na modernidade apresenta-se como um ser complexo e híbrido no pós-moderno que estamos vivenciando. Contudo, ele permanece um ser de símbolos, vivendo e construindo novos imaginários e é desta forma que podemos relacionar o imaginário com o simbólico, sem definições precisas, diz Maffesoli (2001a), mas estabelecer estas relações por aproximações.

O imaginário sempre comunicou o estético na exploração das imagens dos sonhos, dos mitos, pelos processos criativos, assim como possibilitou o encontro de caminhos para a fantasia ou o fantástico. Kant considera que a distinção do que é belo, nós buscamos na faculdade da imaginação e não na faculdade da cognição apenas, mas uma imaginação ligada ao entendimento. E prossegue refletindo que o juízo do gosto, ou do prazer, não se constitui em logicicidade, mas se constitui pelo estético, numa existência humana de forma subjetiva. 
As imagens divulgadas principalmente na mídia, pelas quais consideramos possível perceber novas visualidades do momento contemporâneo constituem-se basicamente na inclusão dos mais diversos estilos visuais, tanto antigos, como novos, elitistas ou populares, gerando uma rede de muitos diferenciais visuais estéticos, bem como a possibilidade de identificação do sujeito, de posicionamento variável e descentrado, manifesto nas representações imagísticas.

Com o surgimento da televisão analógica na década de 20, houve uma discussão de que as imagens televisivas iriam suprimir um veículo de comunicação de massa tão difundido, como o rádio e no entanto tal não aconteceu. A televisão e o rádio passaram a atuar em conjunto um não eliminando o outro, mas englobando-se dentro das empresas que detinham o poder da comunicação. Da mesma forma os $e$ books não eliminaram o livro impresso. É assim que na contemporaneidade as imagens estão cada vez mais entrelaçadas ao mundo visual, virtual e imaginário.

Com o surgimento dessas novas tecnologias de comunicação os sujeitos passaram a vivenciar uma situação prazerosa de união entre as mais diversas possibilidades de contemplação e ao mesmo de participação. É dessa forma que não houve uma rejeição à modernidade, mas uma inclusão da mesma junto às tendências contemporâneas.

No mundo globalizado do contemporâneo, as redes dos computadores, a Internet, poderiam proporcionar um estilo estético partilhando novas emoções ou sentimentos comuns.

A estética visual contemporânea ou pós-moderna vem tendendo à multimídia, à mistura, à hibridação; ao mesmo tempo que cultiva a ambigüidade, a indefinição, a indeterminação, a polissemia das mais diversas formas visuais busca ampliar ao máximo as suas possibilidades conotativas, procura a participação ativa do espectador num jogo de interpretação, ao manifestar visualidades efêmeras e descartáveis, tolera a imperfeição, a imprecisão, a poluição, e as interferências externas pós-produção, valorizando a comunicação e as emoções dos grupos e ironizando sutilmente cânones e estereótipos visuais hegemônicos e banalizados da alta cultura. È possível perceber que as imagens do contemporâneo não se preocupam em apresentar pureza estilística ou em apresentar soluções inéditas de 
vanguarda, pois é resultado da intertextualidade, da citação, da cópia, da hibridação e de vários estilos. Ao mesmo tempo cultiva o grotesco, contradizendo conceitos estruturados de beleza.

Dissolveram-se cânones de reflexões estéticas sobre a beleza, uma das categorias da estética, e novas categorias passaram a fazer parte do pensamento estético, de acordo com Vasquez (1999). A ironia e o grotesco passam a ter novos significados. O que implica que o belo é estético, mas nem todo estético é belo, diz ainda o autor.

É preciso considerar que o homem é constituído pela comunhão entre a razão, a percepção, a sensibilidade, as complexidades, os símbolos, os muitos imaginários culturais e sociais e que estas coisas todas estão imbricadas no seu todo interior, que compõe a estrutura humana e que elas não se encontram em escaninhos separados, como a modernidade postulava. Opondo-nos ao positivismo puro, acreditamos que não existe neutralidade em nossas atitudes e em nosso comportamento. Por mais neutros que desejemos ser, por mais racionais que tenhamos de ser, dificilmente as emoções deixam de participar de nossos julgamentos, das nossas ações. E assim, diz o sociólogo Michel Maffesoli "é que se pode falar em estilo estético que dá ênfase ao sensível e é o suporte das diversas formas de sociabilidade" (Maffesoli, 2001b, p. 57).

Na contemporaneidade torna-se difícil falar em estilo, uma vez que o pósmoderno vivenciado engloba praticamente todos os estilos, num processo de inclusão e, por isso mesmo, o pós-moderno não se constitui em estilo, mas em condição de vida.

Enquanto na modernidade predominou a exclusão, negando valores considerados ultrapassados, na pós-modernidade agregam-se esses estilos estéticos: os shopings centers tornaram-se exemplo internacional destas hibridações; neles vemos colunas dóricas, jônicas, usadas pelos gregos na Antigüidade, juntamente com estruturas metálicas, vidrarias, decorações florais e vegetais, pisos de mármore ou de granito polido, lado a lado com paredes de tijolo à vista. Provavelmente, no futuro, esses shoppings serão os verdadeiros museus criados no século XX. 
Ora, convivemos, então diariamente com este híbrido, nós o aceitamos com naturalidade e, muitas vezes não nos damos conta destas misturas que estão ao nosso redor, e também no interior de nós mesmos. Nossos valores permanecem os mesmos de nossos pais, de nossos ancestrais? Muitos ainda podem dizer que sim num contexto de normas perenes do nosso ser, mas esses valores têm sido re-lidos, reestruturados, decodificados para uma interação maior com o mundo contemporâneo no qual estamos imersos. A religiosidade milenar da cultura judaico-cristã permanece, mas com maior flexibilidade, com maior compreensão. É, novamente a hibridação que está ao nosso redor.

Podemos perceber que, em nosso entorno, as imagens que nos cercam tendem mais à ambigüidade e à indeterminação. Nossas manifestações estão beirando à efemeridade, nosso mundo está fragmentado, há maiores imperfeições do que a busca da perfeição que a modernidade proclamava. As tendências de beleza deram lugar aos produtos da indústria cultural e midiática, e a ironia está por toda a parte.

Se o homem do contemporâneo tudo aceita em nome desta mestiçagem de estilos podemos dizer que o lógico está cada vez mais unido ao sentimento, às crenças, às percepções, às emoções de um imaginário cultural que nos rege, recriando antigos rituais.

Hoje, homem e máquina convivem diariamente: A estética é, pois, feita de qualidade e não apenas de quantidade. Buscamos qualidade de vida, buscamos harmonia com a natureza, enquanto, ao mesmo tempo, nos religamos às máquinas para interligarmo-nos por e-mail com o outro lado do mundo, em segundos. Isso tudo nos dá a idéia de um mundo de paradoxos, de indeterminações, um mundo que podemos chamar de mundo polissêmico.

Tudo isso é motivo de reflexão necessária, para melhor compreendermos o macro universo em que vivemos e isso só será possível se existir em nós uma harmonia interior do eu comigo, um senso de criticidade, para apreender essa velocidade que nos cerca, com um simples toque de mouse ou de um controle remoto.

Kant (Tradução Rodhen, Valério, e Marques, Antonio, 1995), já dizia que na 
representação sensível das coisas fora de mim, a qualidade do espaço no qual nós as instituímos, é aquilo que é simplesmente subjetivo... o espaço é uma parte do conhecimento das coisas como fenômeno. A sensação externa, assim, exprime precisamente o que é subjetivo; a sensação é também utilizada para o conhecimento dos objetos fora de nós... (Kant, 1995, p. 33)

Neste mundo complexo e pleno de velocidade, de espetáculos espetacularizados, de novas tecnologias, em que o imaginário humano volta-se para novas culturas de massa, como a televisão, as imagens do cinema repletas de efeitos especiais, isto tudo se reflete também na estética interior interferindo e, por vezes, confundindo nossas percepções de uma macro estética, transformando-a e tornandoa parte do nosso cotidiano social e cultural. A capacidade de transcendência do ser humano convive com a imanência, com a solidão da pessoa presa em condomínios, utilizando a rede para pagar suas dívidas, para adquirir bens via internet, sem mais necessitar comparecer às livrarias ou aos museus para folhear livros ou contemplar obras de arte. Com o advento do microcomputador, o viver se tornou mais prático e prazeroso: um concerto ao vivo numa sala de espetáculos ou o mesmo concerto num home theater poderá proporcionar a mesma sensação prazerosa de usufruir da beleza estética musical.

Se ainda pudermos cultivar uma harmonia estética interior, ela poderá, sem sombra de dúvida, levar-nos à apropriação de uma percepção maior do mundo, num processo de reconhecimento, de compreensão e de interpretação. É por essa razão que acreditamos ser absolutamente necessário o desenvolvimento harmônico interior do ser humano e da percepção de si mesmo.

A idéia seria de formação da sensibilidade no ser humano, como elemento fundamental como centro e chave de um desenvolvimento estético interior harmônico do sujeito consigo mesmo para uma compreensão maior deste mundo contemporâneo que é tecnológico, epistemológico e sensível e no qual o imaginário vem atuando como realidade social, povoando sonhos, fantasias, e mitos da contemporaneidade. Não vivemos longe deste mundo imaginal a que Maffesoli (2001a) refere, mas o integramos ao nosso dia a dia que se tornou plural.

Mas este mundo mítico-imaginal resistiu ao mundo do pluralismo e transformaram-se os sonhos das muitas culturas quase concentradas numa só, frente 
à globalização tecnológica das artes, das imagens e da comunicação visual contemporâneas.

As tecnologias do imaginário, como a televisão, o cinema, os vídeos, os DVDs, as inúmeras possibilidades de novas visualidades imagísticas computacionais, que desenvolveram-se rapidamente nas últimas décadas, vêm estimulando a imaginação mesmo na aparente racionalidade destes meios de comunicação partilhados pela cultura. Os mitos, então, poderiam ser chamados de uma cosmogonia destas culturas, assim como o sonho, a fantasia, a imaginação, que residem no imaginário.

Entretanto, há a necessidade de uma compreensão maior deste momento contemporâneo, no sentido de valorizarmos o tecnicismo e o sensível estético para pensarmos simultaneamente tanto o prazer de beleza quanto o produto cultural.

É relevante considerar que o caleidoscópio que rodeia o nosso contemporâneo pós-moderno, na velocidade em que vivemos, parece estar sufocando o discernimento daqueles que mergulharam para o seu interior, esquecendo que é mais relevante ser do que ter.

Estudar a estética do imaginário, nas manifestações iconográficas pósmodernas há que resgatar conceitos da modernidade, que sendo um estilo possui paradigmas definidos tais como: O progresso, a avant-garde, a busca pelo novo, pelo único e o original. Buscando o racional, em muitas de suas manifestações, como as da op-art, a modernidade tornou-se exclusivista das tendências anteriores das imagens, conforme Harvey (1992), Connor (1992), Teixeira Coelho (1996), entre outros autores que conceituam suas tendências. Este estilo recusou o kitsch, buscando a linearidade das formas e do pensamento, a ciência, a pureza de uma arte pela arte, mais hermética, com grande reverência à obra única, original e aurática. A pósmodernidade por sua vez, é inclusiva, é uma tendência, ou uma condição que aceita praticamente todas as manifestações do imaginário humano, afirmam ainda os mesmos autores já citados e é uma condição do contemporâneo cuja palavra estilo, ainda é posta em debate. Esta condição pós-moderna, então, valoriza o eclético, a ambigüidade, a polissemia, a hibridização das muitas formas, mantendo um jogo de uma iconografia eclética e buscando a muldidimensionalidade e a liberdade, de 
acordo com os autores referidos, assim também como Bauman, em sua obra $O$ malestar da pós modernidade (1998). Percebe-se ao mesmo tempo, no imaginário visual do pós-moderno, que a divisão entre cultura de elite (a aura artística) e cultura popular, (o kitsch, a colagem) não tem mais sentido, uma vez que a obra híbrida é combinatória e desconstrucionista, alimentada pelo imaginário.

O imaginário pode ser brevemente definido aqui como processo de relação entre o universo subjetivo e a realidade objetiva. De acordo com Gilbert Durand(1998), a realidade é acionada pela presença do imaginário, no qual está contida a imaginação dos muitos processos criativos que assolam a sociedade contemporânea. As novas tecnologias do digital, o computador, a Internet, o correio eletrônico vêm conduzindo o homem a um mundo imaginário e globalizado, ao qual Mc Luhan já desvelara: Se o presente é o futuro do futuro, que surgiu do passado será antevisto por alguns, e, no entanto, será sentido e vivido por todos, muito adiante do seu real. Na modernidade almejava-se um pensamento baseado na razão e na concretude do fato, pregando-se a abolição total da imagem, que pudesse representar uma mentira, uma falsidade (Durand, 1998).

A era das tecnologias uniu sensibilidade com ciência, desenvolveu-se rapidamente, mas a sociedade parece ainda despreparada para exercer domínio sobre esses novos conceitos para investir na vida social, na vida privada e na vida acadêmica ao mesmo tempo. “O imaginário é alimentado por tecnologias” diz o sociólogo Michel Maffesoli (2001a), e se vivemos num mundo complexo, sem verdades absolutas, como afirma Edgar Morin (1998) é pelo imaginário que retornamos às raízes de nossos mais íntimos sentidos, o que nos faz remeter aos sonhos, aos mitos, às fantasias e, assim, a novos conceitos estéticos.

Será nesta nova forma de conceituar a estética relacional da pósmodernidade que nos permitiremos expressar e viver muitas possibilidades do nosso ser: o sonho, o lúdico, o imaginário que permeiam o pensamento atual, ao lado do conhecimento, dos sentimentos e da percepção que podem melhor elucidar a pósmodernidade. Se a modernidade era mais envolta na aura, na exclusão das tendências anteriores, a pós-modernidade agrega em si um novo imaginário, pondo "a descoberto um real oculto e desconhecido, escondido sob o real conhecido, 
'natural'. [O imaginário] faz com que vejamos... outras realidades que não estamos habituados" (Malrieu, 1996, p. 81).

Desta forma o imaginário estabelece um diálogo, uma nova perspectiva entre o emissor e o receptor e, "na medida em que se atribui a missão de comunicar... [o sujeito social] precisa se servir de alusões ao que os outros podem conhecer ou reconhecer" (Huyghe, 1986, p. 24).

A pós-modernidade, sem dúvida, vem trazendo maior liberdade, maiores possibilidades de argumentações, se formos educados a questionar para obtermos compreensão maior da complexidade que nos cerca, sem os padrões e regras rígidas que regiam alguns aspectos da arte na modernidade, com a qual ainda convivemos. É preciso, portanto, conviver e melhor aceitar estas contradições que nos cercam.

É evidente que somos imperfeitos, que muitas vezes desejamos muito mais ser compreendidos do que compreender nas muitas incertezas que nos rodeiam. É difícil nossa busca de harmonia, mas se quisermos, se nos empenharmos em ampliar nossa visão sobre nós e sobre o mundo, em constante movimento para melhor determinar nosso olhar sobre esta condição ainda incerta, de uma pós-modernidade que nos cerca, talvez possamos dizer: eu posso .

Merleau-Ponty refere sobre o

Que seria a visão sem nenhum movimento dos olhos, e como o movimento destes não haveria de baralhar as coisas se, por sua vez, fosse reflexo ou cego, se não tivesse suas antenas , sua clarividência, se a visão não se precedesse nele? Todos os meus deslocamentos por princípio, figuram num canto da minha paisagem, são transladados no mapa do visível. Tudo o que eu vejo por princípio, está a meu alcance, pelo menos, ao alcance do meu olhar, assinalados no mapa do EU POSSO. Cada um dos dois mapas é completo. O mundo visível e o mundo dos meus projetos motores são partes totais do meu Ser.(Merleau-Ponty, 1997, p.260)

O “posso" que o autor enfatiza vai ao encontro das idéias de Bauman (1998), quando afirma que a pós-modernidade é, em última instância, o desejo da liberdade. Nas tendências das manifestações visuais pós-modernas há um posicionamento lúdico, cético, relativista, informal, tolerante e irônico dos artistas das representações pós-modernistas, que se recusam a adotar uma postura elitista, universalista, dogmática. Por outro lado também observamos uma forte tendência desses artistas 
da comunicação iconográfica, de marcarem suas representações com imagens baseadas em suas experiências e preferências individuais transitórias, que afirmam e respeitam o valor da singularidade de cada um, com obras efêmeras, numa espécie de jogo imagístico em que a flexibilidade se manifesta de forma livre e espontânea, e que não pretendem servir de modelos permanentes de representação universal.

Mais que uma simples opção estilística, essas novas tendências mostram que o sujeito pós-moderno é instável, contraditório, flexível, assim como suas representações, e que a nova visualidade das imagens que representam são tão complexas quanto sua própria subjetividade.

Sem obedecer aos cânones determinados pela visão exclusivista moderna ou a busca de uma universalidade, que o modernismo preconizou, o pós-moderno vem perseguindo "o desejo de liberdade" já referido por Bauman (1998), na manifestação de linguagens utilizadas para expressar-se iconograficamente, em que pese sobre si, muitas vezes, a denúncia do anárquico. O excêntrico, as incertezas, os jogos do acaso, que podem ser aparentes na condição pós-moderna, tornam-se alimento de uma liberdade de ação frente ao estabelecido, uma liberdade de expressão e, principalmente, uma liberdade de pensamento, em que o imaginário está presente, conduzindo o sujeito do pós-moderno às próprias raízes de sua existência.

Diz Maffesoli (2001b) que o cotidiano não exclui os sentimentos, "não os acantona na esfera do privado. Teatraliza-os, faz deles uma ética da estética". (Bauman, 1998, p. 125).

Se a estética tratava da beleza, do que é prazeroso às nossas emoções evocamos Plotino (204/5-270) em sua obra $A$ alma, a beleza e a contemplação (Tradução Quiles, 1981) quando refere que os "corpos, com efeito, algumas vezes nos parecem belos e outras não, como se ser corpo fosse coisa diferente de ser belo. Em que consiste esse ser belo que habita os corpos? ” (p. 54).

Para o filósofo, a beleza não se configurava apenas na simetria, nas proporções harmônicas, que os estóicos defendiam teoricamente. Criticando profundamente essa teoria, Plotino confere à estética um novo sentido de onde vai descender o mundo corpóreo. É assim que ele considera a beleza do corpo no seu 
conjunto e nas suas partes. Para ele a beleza vai depender da participação de uma idéia.

Essas reflexões são extremamente pertinentes ao contemporâneo, e é assim que podemos fazer uma autocrítica à nossa formação modernista, que tende a considerar apenas a beleza estética das obras auráricas, das obras já consagradas, muitas vezes rejeitando e criticando manifestações da arte contemporânea, por não compreendermos essa ambigüidade, esse jogo de imagens, essa efemeridade, essa aparente desordem, esse desejo de ser liberto, como alguns aspectos que caracterizam a visualidade pós-moderna.

Maffesoli é ainda mais enfático:

Podemos reconhecer a beleza da fealdade desde o momento em que a relativizamos: pomo-la em relação no quadro de uma globalidade.É efectivamente isso a característica do trágico. Ele não funciona 'a priori' a partir de um cânone preestabelecido, mas vai reconhecer, de uma maneira incessante ou quase consciente, que pode existir uma certa ordem no seio da desordem (Maffesoli, 2001b, p.131).

E acrescenta que "a aceitação da beleza, até e inclusive na sua fealdade, é, na realidade, uma boa propedêutica para um fantástico global”. (Maffesoli, 2001b, p. 132).

Com essas reflexões não queremos afirmar que tudo é esteticamente belo no mundo contemporâneo, como não o foi na Antigüidade ou na Modernidade. Há que saber encontrar o ponto chave para o encontro do prazer estético no mundo globalizado de hoje, conhecer as manifestações iconográficas do homem, descobrir que a necessidade de autonomia que o ser humano quer representar exige uma reflexão maior sobre o estético existente no pós-moderno.

Se estamos em busca de uma estética que perpassou a visualidade aurática, caracterizando a maior parte da História da Humana, não a encontraremos no pós-moderno.

Se a modernidade rompeu com as tradições institucionalizadas em períodos anteriores ao século XIX a generalização das "verdades" numa concepção positivista e racionalista, levaram ao cientificismo que imperava 
pragmaticamente, impondo leis de construção imagística que tolhiam a liberdade para um imaginário social e, por conseqüência, cultural.

É por essas e outras tantas razões já discutidas, que consideramos relevante para o sujeito do iconográfico pós-moderno, uma visão ampla do conhecimento da história humana, da história das idéias e da história das imagens para poder desenvolver suas novas visualidades de experimentação, de releituras e de reestruturações das imagens. Na busca de uma liberdade estão implícitos riscos a correr e a assumir, mas este assumir pressupõe uma consciência crítica frente às tantas incertezas do "ser liberto", pois, como refere Bauman:

Uma vez que a liberdade toma o lugar da ordem e do consenso como critério de qualidade de vida, a arte pós-moderna ganha muitos pontos. Ela acentua a liberdade por manter a imaginação desperta e, assim, manter as possibilidades vivas e jovens. Também acentua a liberdade ao manter os pricípios fluidos, de modo que não se petrificassem na morte e nas certezas enceguecedoras(Bauman, 1998, p.136).

Este desejo de liberdade já se manifestara na Renascença, por exemplo, Giuseppe Arcimboldo (1527-1593) que reuniu os mais diversos objetos estranhos, registros de pessoas com anomalias físicas (desde anões até gigantes), animais, frutas, legumes de diversas espécies, provindos de todos os continentes. Arcimboldo teve condições de fazer estudos para suas obras, observando o pormenor de cada elemento, representando-os em seus mais ricos e finos detalhes. Já aparecia, nessas obras, uma visualidade estética voltada para o grotesco, fugindo aos padrões convencionais de beleza. (Figura 1)

“O grotesco ocorre em uma ampla prática artística que extrai de uma pintura ornamental romana, descoberta em fins do século XV, a qual foi denominada de grottesca, derivação do substantivo italiano grotta (gruta).” (Vasquez, 1999, p. 285).

No grotesco, portanto, afirma ainda Vasquez, é que se manifestam imaginários fantásticos, estranhos e irreais que são produzidos e combinados de forma heterogenea, "embora os elementos que se misturem ou combinem sejam reais" (p. 290). Neste

distanciamento do real que põe em dúvida sua consistência, o grotesco se acha aparentado com o cômico e mais de um tratadista o 
inclui nessa categoria. $\mathrm{O}$ fato é que às vezes se assemelha à sátira, mas seu distanciamento da ordem normal, cotidiana, e seus componentes de horror, estranheza ou antinaturalidade, o aproximam mais do feio, do monstruoso, que do exatamente cômico. O grotesco é um dos meios de que a arte e a literatura dispõem para ajudar a quebrar uma realidade que, indiferente ao tempo e à mudança, se empenha em ser eterna e imutável. (Vasquez,1999, pg.291)

O absurdo, o irracional, o próprio centro de uma realidade constituem-se nessa nova visualidade que poder-se-ia chamar de grotesca associada aos meios de representação visual de nossa contemporaneidade. Um exemplo é o escultor Ron Mueck, que ultiliza efeitos especiais cinematográficos para criar obras de arte. São extremamente realistas e se não fosse a dimensão das esculturas seria fácil confundilas com pessoas vivas. Australiano, nascido em Melbourne em 1958, iniciou seu trabalho artístico fazendo e manipulando marionetes, orientado pelos pais. Depois passou a fazer bonecos de vários tamanhos para campanhas publicitárias. Nos Estados Unidos, trabalhou com efeitos especiais no Muppet Show e Vila Sésamo. Salientou-se no mundo das artes depois de uma exposição em Londres, onde chamou a atenção da crítica ao exibir a escultura Dead Dad. A obra possui dois terços a mais do que o tamanho natural de um ser humano e retrata o corpo nu de seu pai após a morte. As dimensões de suas obras podem ser vistas na Figura 2, salientando que o hiperrealismo perpassa todo o seu trabalho e retrata uma hibridação entre o estilo citado e o grotesco, em que as características do contemporâneo pós-moderno são evidentes. As peças são feitas em fibra de vidro, silicone, rezina acrílica e poliéster.

Essas imagens parecem-nos claras para o encontro de uma nova visualidade estética do século XXI, no qual podemos encontrar faculdades sensitivas, seja no híbrido ou no complexo, na multiplicidade ou na ambigüidade, em busca de participação interativa entre sujeito e forma visual.

Se não encontramos a perfeição na representação iconográfica do contemporâneo, como era a exigência dos cânones da modernidade, o imaginário da cultura ocidental pós-moderna inclusivo e mais liberto aceita imperfeições, muitas vezes propositais, pois que elas podem ampliar significações das representações visuais. Essa parece ser a busca da liberdade na construção e na recriação das imagens, que vem encontrando novos caminhos de expressão em novos imaginários, 
os quais estão traduzindo, reinterpretando e, por isso mesmo, transformando conceitos estéticos em novas possibilidades imagísticas, antes interditadas.

Vivendo a pluralidade, não existe mais a beleza ou a verdade únicas. Diz Maffesoli (2001b) que essa beleza antes sacralizada e bem definida como tal tornouse polissêmica e dessa forma com características polivalentes, o que significa que as grandes verdades deixaram de existir para dar lugar à complexidade e à ambivalência. A emoção e os sentimentos humanos podem tornar belo, e, portanto, estético, o objeto de arte. Por ser diferenciado dos cânones estabelecidos na modernidade, não serão esses objetos ou formas representativas menos belos aos nossos olhos se assim o desejarmos. O estabelecimento de relações entre o que é e o que poderá vir a ser, não mais depende apenas das teorias desenvolvidas, mas da união entre conhecimento, emoção, imaginário, participação, interação do próprio eu com o objeto ou a forma visual.

\section{Conforme Maffesoli,}

O imaginário é algo que ultrapassa o indivíduo, que impregna o coletivo ou, ao menos, parte do coletivo. (...) O imaginário é o estado de espírito de um grupo, de um país, de um Estado-nação, de uma comunidade, etc. O imaginário estabelece vínculo. È cimento social. Logo, se o imaginário liga, une numa mesma atmosfera, não pode ser individual. (Maffesoli, 2001 ${ }^{\mathrm{a}}$, p.76)

Esta é a razão pela qual as imagens pós-modernas vêem estabelecendo um “cimento" no imaginário de diversos grupos de espectadores participantes do contemporâneo, que, dependendo da cultura onde está inserido, aceita, partilha e por isso mesmo percebe a nova visualidade que se apresenta com novas expectativas estéticas.

Acreditamos que será nessa nova forma de pensar que poderemos conceituar uma nova estética relacional da pós-modernidade, o que nos permitirá expressar e viver muitas possibilidades do nosso ser, com o conhecimento e o espírito crítico e reflexivo, assumindo sempre os riscos que a liberdade iconográfica nos vem proporcionar. 


\section{Referências Bibliográficas:}

BAUMAN, Zygmunt. O mal-estar da pós-modernidade. Rio de Janeiro: Zahar, 1998.

CONNOR, S. Cultura pós-moderna. Introdução às teorias do contemporâneo.

São Paulo: Loyola, 1992.

DURAND, Gilbert. O imaginário. Ensaio acerca das ciências e da filosofia da imagem. Rio de Janeiro: Difel, 1998.

HARVEY, David. Condição pós-moderna. São Paulo: Loyola, 1992

HUYGHE, René. O Poder da Imagem. Lisboa: Ed. 70, 1986.

KANT, Immanuel. Trad. Rodhen, Valério, e Marques, Antonio. Crítica da faculdade do juízo. Rio de Janeiro: Forense Universitária, 1995.

MAFFESOLI, M. O imaginário é uma realidade .Revista Famecos. Mídia cultura e tecnologia. $\mathrm{n}^{0} 15$, ago. 2001(a). Porto Alegre: EDIPUCRS, p.74-81.

. O eterno instante. $O$ retorno do trágico nas sociedades pósmodernas. Lisboa: Instituto Piaget, 2001(b).

MALRIEU, Philippe. A construção do imaginário. Lisboa: Instituto Piaget, 1996.

MERLEAU-PONTY, Maurice. O olho e o espírito. In: Duarte, Rodrigo (org) O belo autônomo. Belo Horizonte: Editora UFMG, 1997, p. 257-286.

MORIN, Edgar. O método. Porto Alegre: Sulina, 1998.

PLOTINO. A alma , a beleza, a contemplação. Sobre o belo, Enéada, I,6. Trad. Quiles, Imael. São Paulo: Associação Palas Atena, 1981.

TEIXEIRA COELHO, José. Moderno Pós-Moderno. São Paulo: Illuminuras, 1996.

VASQUEZ, Adolfo Sanchéz. Convite à estética. Rio de Janeiro: Civilização Brasileira, 1999. 


\section{Anexos:}

Figura 1:

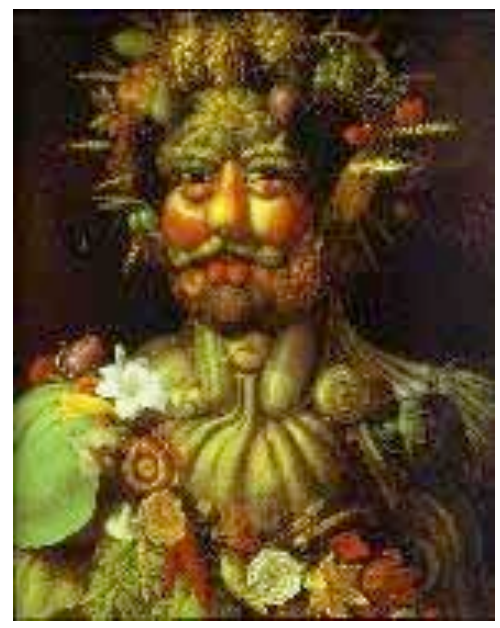

Giuseppe Arcimboldo

"Vertumnus" (1590 - 1591)
Figura 2:

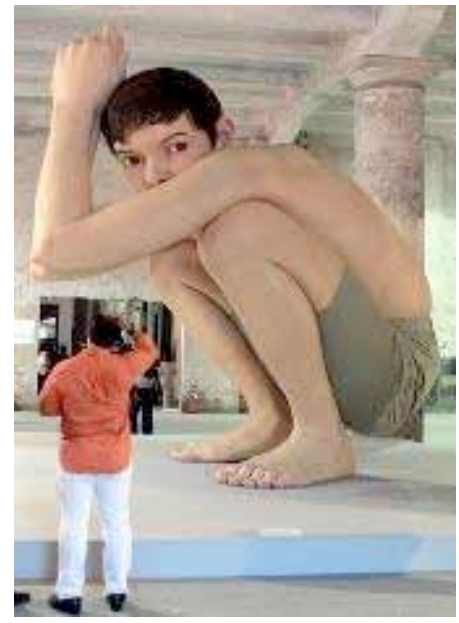

Ron Mueck

“Menino Agachado” (2001) 